\title{
Addressing sleep disorder of autistic children with Qur'anic sound therapy
}

\author{
Mohd Amzari Tumiran', Siti Patonah Mohamad", Rohaida Mohd Saat ${ }^{2^{\star}}$, \\ Mohd Yakub Zulkifli Mohd Yusoff ${ }^{1}$, Noor Naemah Abdul Rahman', \\ Durriyyah Sharifah Hasan Adli ${ }^{3}$
}

\footnotetext{
${ }^{1}$ Academy of Islamic Studies, University of Malaya, Kuala Lumpur, Malaysia

${ }^{2}$ Faculty of Education, University of Malaya, Kuala Lumpur, Malaysia; * Corresponding Author: rohaida@um.edu.my

${ }^{3}$ Faculty of Science, University of Malaya, Kuala Lumpur, Malaysia
}

Received 19 June 2013; revised 20 July 2013; accepted 11 August 2013

Copyright (C) 2013 Mohd Amzari Tumiran et al. This is an open access article distributed under the Creative Commons Attribution License, which permits unrestricted use, distribution, and reproduction in any medium, provided the original work is properly cited.

\section{ABSTRACT}

Autism is a neural development disorder characterized by the deterioration in social interacttion, abnormal language expression, repetitive actions, imaginative game tendencies, and limited and/or obsessiveness in certain activities/ interests. Lack of sleep is one of the factors contributing to the worsening of overall negative symptoms of autistic children. From the Islamic perspective, sleep is a necessity and could function as a treatment for health problems, in addition to influencing behavior patterns. Sound therapy has been used in dealing with various health problems, including sleep problems and mental ill health. Possibly, it can also address sleep problems of the autistic children. Listening to the melodious Qur'anic recitation is known to have therapeutic effects even on individuals who do not understand the meaning of the verses being read; it could function as sound therapy. However, no established work has been done to study the effect of Qur'anic verses recitation on autistic children and their sleep problems. Similar to the use of music therapy, Qur'anic recitation is also expected to have a positive impact on speech, learning and interpersonal relationship. As a healing medium, Qur'anic therapy is also expected to have a better result as compared to other conventional sound therapy since its content could be psychotherapeutic.

Keywords: Sleep Disorder; Autism; Qur'anic Therapy; Sound Therapy

\section{INTRODUCTION}

Autism is a neural development disorder characterized by the deterioration in social interaction, abnormal language expression, repetitive actions, imaginative game tendencies and limited and/or obsessiveness in certain activities and interests [1]. It is a chronic psychiatric disorder of childhood that usually begins before the age of three years. Approximately $1 \%$ of children general population has autistic spectrum disorder [2-6].

It has been reported that a feature of autistic problem is sleep disturbance; involving approximately $44 \%-83 \%$ of its population [7]. Lack of sleep has been reported as one of the factors contributing to the worsening of negative symptoms of children with autism. Disturbance of the sleep behavior will subsequently affect an autistic person's cognitive ability and his daily routine [8-10]. Some studies suggested that improving sleep quality [7, 11-13] could actually reduce negative emotional tendencies like aggressive behaviors, tantrums and self-inflicted injury [14].

Music therapy as part of complementary and alternative medicine (CAM) has been used to address sleep problem [15-17]. Past studies showed that music therapy has a positive effect on the development of emotional and interpersonal abilities [18-20]. This treatment has been reported to assist children in two-way interaction, tolerance, social flexibility and other interpersonal skills depending on the approach used [21-23].

This paper submits the potential therapy of the melodious Qur'anic recitation for sleep disorder among autistic children. Besides that, this paper suggests the Qur'anic recitation functioning as sound therapy for sleep disorder among autistic children, based on the positive impact of music therapy as sound healing for certain mental disorders. 


\section{MENTIONS OF SLEEP IN QUR'AN}

Antagonistic relationship between conventional medicine and religion since the time of the Renaissance ceased to exist in Islamic science through Qur'an and works by Muslim scholars [24-27]. Qur'an, the holy book of Islam is accepted by the Muslim community as an antidote and healing medium, especially for mental related illness [28,29].

The use of Qur'anic therapy as a cure has been described in several verses of the Qur'an, as below:

1 ... Say: "It is a Guide and a Healing to those who believe; and for those believe not, there is a deafness in their ears, and it is blindness in their eyes: they are (as it were) being call a place far distant."

(Qur'an 41:44)

Islam advocates conventional medical therapy to be accompanied by recitation of Qur'anic verses; serving as psychospiritual therapy [28,30-32]. The Qur'an, which functions as guidance for Muslims, has stated clearly in certain verses that sleep phenomena has significant role in man's daily lives.

"And We have made your sleep [a means for] rest."

(Qur'an 78:9)

Hence, from the Islamic perspective it is clear that man needs sleep because the Creator has made it as part of human nature $[33,34]$ and, in addition, its importance for the well-being of the body has been well established by conventional science. Scientifically, adequate sleep has been reported to be very important to human health. Thus, sleep can be part of health treatment, providing physical and mental rest [35].

Lack of sleep will affect the human immune function, making the body vulnerable to infections/diseases [36], besides the early impression of aging [37]. It is also one of the factors contributing to several acute and chronic diseases, such as breast cancer [38] and heart failure [39].

As for recitation of the Qur'an, it is typically done with various tarannum or song/melody. Hence, sound therapy involving listening to melodious Qur'anic recitations could be functioning as an antidote and/or a healer (e.g. Qur'an 17:82; 41:44; 10:57).

\section{SLEEP DISORDER OF AUTISTIC CHILDREN}

Sleep disturbance is a significant problem for children with autism [40]. Sleep patterns also differ among same preschool kids with autistic and deterioration of neural development [41].

Scientific reports state that the various sleep disorders could lead to negative implications [42-46] and contrib-

\footnotetext{
${ }^{1}$ Translations of the Qur'an in this verse and the rest are based on the reference of Abdullah Yusuf Ali from:

http://www.Qur'an4u.com/Qur'an_english_Yeh.htm
}

ute to the increase in negative valences in autistic children $[47,48]$. These sleep disturbances influence negatively on the behavior patterns of a child with autism.

The aspects of sleep problems/disturbances faced by autistic children are very much related to the quality of their sleep, duration and period of sleep. It has been reported that they have abnormal sleep patterns and sleep disorders $[11,49]$, such as requiring certain duration of sleep time (time required for deep sleep) [50], sleep disturbance threshold when almost asleep [51], low quailties of sleep [52], waking up at midnight or too early [53] and abnormal sleep routine [54].

Relationship between behavior and sleep problems in autistic child has been proposed [51]. This is based on studies focusing on the effectiveness of care and sleep problems in children with autism. The presence of insomniac symptoms in autistic children has been identified. In addition, a positive relationship between quality of sleep with affective problems and reduced social interaction has been reported among autistic children. Hence, sleep disorders and low quality sleep of autistic children could worsen their negative behaviors [6].

Approximately $43 \%$ - $68 \%$ of autistic children experienced sleep epilepsy [52]. This high percentage may be due to genetic factors. Nevertheless, the absence or lack of similarity of electroencephalogram (EEG) between an autistic child with his/ her siblings indicates that genetic is not the only factor to explain the abnormality of EEG frequency in children with autism. A longitudinal population-based study suggested problems with sleep cycle stages of sleep exist in children with autism [6,53].

Symptoms of fear during sleep "sleep terrors" are also found to be a nuisance to normal sleep of autistic children, i.e. waking up suddenly during low state EEG wave, followed by manifestation of fear such as screaming and crying. This situation could possibly be a reflection of the problems they faced during the day and subsequently expressed unconsciously in their sleep. Sleep terrors can lead to distraction for patients and family from the real problems [49].

To date, researches focusing on sleep problems among adults with autism are less compared to researches involving children with autism. This might be due to the misdiagnosed of the disorder; being considered a habit and, in addition, behavioral adaptations keep the situation hidden [47].

\section{RESEARCH METHODOLOGY FOR SLEEP DISORDER OF AUTISTIC CHILDREN}

A list of methodologies used for research in sleep disorder of autistic children is shown in Table 1. Two main categories have been used in studies which deal with sleep disorders among autistic children [55]: 1) subjec- 
Table 1. Studies on sleep disorders involving autistic individuals and the instruments used [58,66-69].

\begin{tabular}{cccc}
\hline Researcher (Year) & Instrument & $\begin{array}{c}\text { Respondent } \\
\text { age }\end{array}$ & $\begin{array}{c}\text { Respondent } \\
\text { status (n) }\end{array}$ \\
Allik et al. (2006) & Actigraphy & $8-12$ & AS $^{\mathrm{a}}(32)$, \\
$\begin{array}{c}\text { Cotton \& } \\
\text { Richdale (2010) } \\
\text { Taylor } \text { et al. } \\
(2012)\end{array}$ & $\begin{array}{c}\text { Background information } \\
\text { questionnaire, sleep diary }\end{array}$ & $3-16$ & Autism (34) \\
$\begin{array}{c}\text { Park et al. (2012) } \\
\text { BeDS }\end{array}$ & $\begin{array}{c}\text { Parent report } \\
\text { questionnaire }\end{array}$ & $1-10$ & Autism (219) \\
Tsai et al. (2012) & CSHQ $^{\mathrm{c}}$ & $6-15$ & Autism (166) \\
\hline
\end{tabular}

${ }^{\mathrm{a}}$ AS: Asperger Syndrome. ${ }^{\mathrm{b}}$ BEDS: Behavior Evaluation of Sleep Disorder. ${ }^{\circ}$ CSHQ: Children's Sleep Habits Questionnaire.

tive style: inquired questionnaire and reports from parents with autistic child about their children sleep activity [47]; 2) objective style: involved measuring instruments for sleep-wake cycle such as cyclic polysomnography (PSG), actigraphy and videosomnography [56]. The same methods have been applied for identifying sleep patterns of individuals with Asperger's syndrome (aged 15 - 25 years) [47] and assessing sleep-wake patterns involving hormonal imbalance in autistic children who also exhibited a circadian rhythm system degradation [11].

Compared to objective assessment, administration of subjective assessment is more common. In the latter, three types of methods used: 1) sleep diary, 2) single-item response, and 3) children's sleep habits questionnaire (CSHQ). Data collection through subjective assessment, e.g. using sleep diary is useful [55,57-59] since it reflects the views and opinions of parents/ guardians of the children. Although data from monitored autistic children is considered important, it is usually proven to be less precise due to some oversight by guardians [56].

In studies conducted using actigraphs to examine children with autism, it was proposed that the data related to reports on sleep patterns and sleep disorders of children by parents alone might not be accurate as compared to actigraphy $[60,61]$. Actigraphy, which can be mounted like a watch on the wrist or leg to analyze sleep-wake cycle, is one of the few instruments used to collect objective data for studies involving autistic children. Others have also suggested that the data from actigraphy and sleep diary $[55,60-63]$ as to be more appropriate compared to data obtained from questionnaires [56].

Although objective style research for data collection using actigraph is more preferred compared to PSG and videosomnography because of its user friendliness, suitability for children and cost effectiveness, videosomnography is said to have better readings $[64,65]$. In addition, it is very useful in providing better information about night sleep and serves as the main data provider and support when dealing with sceptical reports [56].

\section{QUR'ANIC RECITATION AS SOUND THERAPY}

Sound therapy has been used to address various health problems [70], especially in relation to depression [71], pain management [72], emotional and psychological problems [23], traumatic brain injury [73] and stroke recovery [74]. Almost every research done by scientists related to sound therapy applied elements of music or instruments to trigger the reactions of subjects being studied [75]. For example, an experiment was done to see the response of foetus towards music and its impact on the heart rate and foetal movement. Auditory system proves to be responsive and plays a role, starting as young as eight months in the womb [76]. In the Islamic tradition, pregnant mothers are encouraged to read certain Qur'anic chapters (e.g. chapter Maryam and Yusuf) during pregnancy. It can be assumed that the foetus in the womb is being stimulated by the melodious recitation of the Qur'anic verses. In fact, Qur'anic verses describing the creation of man are normally initiated with narration on the ability to listen, prior to narration on the ability to see and think.

"And Allah brought you forth from the wombs of your mothers when you knew nothing, and $\mathrm{He}$ gave you hearing and sight and feeling (common sense) so that you may be grateful."

(Qur'an 16:78)

Music as sound therapy plays a significant role especially in the field of psychology. It is also recognized by Muslim scholars, especially during the golden era of Islamic civilization. Some Muslim scholars such as Al-Farabi and Al-Kindi were involved in the science of music [77].

Qur'anic recitation has the effect as therapy and relaxation to an individual even if the person does not understand the meaning of the verses being read [78]. Unfortunately, very few studies have been done involving recitation of Qur'an as auditory system stimulant, even though Qur'an could function as sound therapy [79]. As sound therapy, it is expected to have similar effects as music. For Muslim autistic children, they could also vocalized the Qur'anic recitations and, hence, making it part of speech therapy.

The potential of the sound and melody from Qur'anic recitation in shaping a person's emotion and psychology has its basis in Islamic history. For example, the fierce personality of Prophet Muhammad's companion, Umar Al-Khattab, before his conversion to Islam changed when he first heard verses of Qur'an recited by his sister [79]. Similar to music therapy, the melodious sound of Qur'anic therapy has a therapeutic effect to address emotional, cognitive and social needs of individuals.

Muslims believe that as the biggest miracle revealed to the Prophet Muhammad [80], the Qur'an is extremely 
special not only in its content/substance, but also through the acts of reading and listening to its verses. For example, there are studies reporting the positive effect of listening to Qur'anic recitation on a sleepy driver [81] and the effect of reciting the Qur'an on mental health [82]. When comparing between listening to Qur'anic recitation or music, higher percentage of alpha waves were generated by the former $[83,84]$. Alpha waves have been associated with the state of inner peace, for example the link was demonstrated through meditation [85]. Since listening to Qur'anic recitations and/or doing the recitations are able to increase the level of inner peace to an individual, Qur'anic therapy can be beneficial to autistic children who have emotional problems [84]. As an alternative sound therapy, Qur'anic verses, with specific messages/contents, have added values for its listeners, including autistic children. A study has shown that different brain parts will be activated depending on the type of audio stimulation a person received [86]. Table 2 showed different brain areas being activated in normal and autistic individuals. Parts of the brain that function in determining speech ability and understanding the information received are Broca's and Wernicke's areas in the brain left hemisphere [36]. These parts are located in the frontal and temporal lobes, where they are closely located to the organ of hearing itself, the ears.

Even for the autistic children, the ability to recite selected Quranic verses is also considered a necessity for some Muslim prayer rituals. Thus, the recitation of Qur'an, itself, could be considered as speech training; a type of speech therapy. It is worth noting that for autistic children, listening to repeated sentences activated left precentral gyrus, which is the primary motor gyrus (Table 2). If the recitation of the Qur'an is repeated many times, it will also register in the long-term memory [87, 88].

Having memorized Qur'anic verses or successful in hafazan (Arabic term for memorization) is considered as

Table 2. PET brain mapping based on audio stimulation [86].

\begin{tabular}{|c|c|c|}
\hline \multirow{2}{*}{$\begin{array}{l}\text { Type of Audio } \\
\text { Stimulus }\end{array}$} & \multicolumn{2}{|c|}{$\begin{array}{c}\text { Brain Areas Activated } \\
\text { (via Positron Emission Tomography/PET) }\end{array}$} \\
\hline & Normal individual & Autistic \\
\hline $\begin{array}{l}\text { A pseudorandom } \\
\text { sequence of tones }\end{array}$ & $\begin{array}{l}\text { Primary and } \\
\text { secondary } \\
\text { auditory cortex }\end{array}$ & $\begin{array}{l}\text { - Left anterior cingulate } \\
\text { gyrus }\end{array}$ \\
\hline Simple sentences & $\begin{array}{l}\text { Left lateral } \\
\text { temporal cortex }\end{array}$ & $\begin{array}{l}\text { - } \text { Right middle frontal } \\
\text { cortex } \\
\text { - } \quad \text { Left superior temporal } \\
\text { gyrus }\end{array}$ \\
\hline $\begin{array}{l}\text { Repeated } \\
\text { sentences }\end{array}$ & $\begin{array}{l}\text { - } \\
\text { cortex } \\
\text { - Left primary } \\
\text { sensorimotor } \\
\text { cortex }\end{array}$ & - $\quad$ Left precentral gyrus \\
\hline
\end{tabular}

to have reached a high merit in Islam. Such an achievement gives a sense of pride to both the memorizer and his/her family.

\section{CONCLUSION}

Qur'anic sound therapy for autistic children has not yet been established. However, this kind of therapy could adapt the same concept as music therapy. Past researches showed that music as sound therapy has a positive impact on speech, learning and interpersonal relationship. Qur'anic therapy is expected to have better results compared to other conventional sound therapies, since it produces alpha waves higher when listening to music. Hence, it is recommended that Qur'anic therapy be studied as a healing medium in addressing sleep problems of autistic children and also their emotional problems.

\section{ACKNOWLEDGEMENTS}

The authors are grateful to the University of Malaya for research grants UMRG RG059/09 AFR and PG062- 2012B.

\section{REFERENCES}

[1] El-Baz, F., Ismael, N.A. and Nour El-Din, S.M. (2011) Risk factors for autism: An Egyptian study. The Egyptian Journal of Medical Human Genetics, 12, 31-38. doi:10.1016/j.ejmhg.2011.02.011

[2] Baird, G., Simonoff, E., Pickles, A., Chandler, S., Loucas, T., Meldrum, D. and Charman, T. (2006) Prevalence of disorders of the autism spectrum in a population cohort of children in South Thames: The special needs and autism project (SNAP). Lancet, 368, 210-215. doi:10.1016/S0140-6736(06)69041-7

[3] Baron-Cohen, S. (2007) About 1\% of children in the South Thames region have an autistic spectrum disorder. Evidence-Based Mental Health, 10, 28. doi:10.1136/ebmh.10.1.28

[4] Baron-Cohen, S., Scott, F.J, Allison, C., Williams, J., Bolton, P., Matthews, F.E., et al. (2009) Prevalence of autism-spectrum conditions: UK school-based population study. British Journal of Psychiatry, 194, 500-509. doi:10.1192/bjp.bp.108.059345

[5] Honda, H., Shimizu, Y. and Rutter, M. (2005) No effect of MMR withdrawal on the incidence of autism: A total population study. Journal of Child Psychology and Psychiatry, 46, 572-579. doi:10.1111/j.1469-7610.2005.01425.x

[6] Sivertsen, B., Posserud, M.-B., Gillberg, C., Lundervold, A.J. and Hysing, M. (2012) Sleep problems in children with autism spectrum problems: A longitudinal population-based study. Autism, 16, 139-150. doi:10.1177/1362361311404255

[7] Williams, P.G., Sears, L.L. and Allard, A. (2004) Sleep problems in children with autism. Journal of Sleep Research, 13, 265-268.

doi:10.1111/j.1365-2869.2004.00405.x 
[8] Dominicka, K.C., Davis, N.O., Lainhart, J., Tager-Flusberga, H. and Folsteind, S. (2007) Atypical behaviors in children with autism and children with a history of language impairment. Research in Developmental Disabilities, 28, 145-162. doi:10.1016/j.ridd.2006.02.003

[9] Polimeni, M.A., Richdale, A.L. and Francis, A.J. (2005) A survey of sleep problems in autism, Asperger's disorder and typically developing children. Journal of Intellectual Disability Research, 49, 260-268. doi:10.1111/j.1365-2788.2005.00642.x

[10] LeBlanc, L.A. and Gillis, J.M. (2012) Behavioral interventions for children with autism spectrum disorders. $P e$ diatric Clinics of North America, 59, 147-164. doi:10.1016/j.pcl.2011.10.006

[11] Glickman, G. (2010). Circadian rhythms and sleep in children with autism. Neuroscience and Biobehavioral Reviews, 34, 755-768. doi:10.1016/j.neubiorev.2009.11.017

[12] Chou, M.-C., Chou, W.-J., Chiang, H.-L., Wu, Y.-Y., Lee, J.-C., Wong, C.-C., et al. (2012) Sleep problems among Taiwanese children with autism, their siblings and typically developing children. Research in Autism Spectrum Disorders, 6, 665-672. doi:10.1016/j.rasd.2011.09.010

[13] Cortesi, F., Giannotti, F., Ivanenko, A. and Johnson, K. (2010) Sleep in children with autistic spectrum disorder. Sleep Medicine, 11, 659-664. doi:10.1016/j.sleep.2010.01.010

[14] Research Units on Pediatric Psychopharmacology Autism Network (2002) Risperidone in children with autism for serious behavioral problems. New England Journal of Medicine, 347, 314-321. doi:10.1056/NEJMoa013171

[15] Levy, S.E. and Hyman, S.L. (2008) Complementary and alternative medicine treatments for children with Autism Spectrum Disorders. Child \& Adolescent Psychiatric Clinics of North America, 17, 803-820. doi:10.1016/j.chc.2008.06.004

[16] Wong, H.H.L. and Smith, R.G. (2006) Patterns of complementary and alternative medical therapy use in children diagnosed with autism spectrum disorders. Journal of Autism and Developmental Disorders, 36, 901-909. doi:10.1007/s10803-006-0131-0

[17] Levy S.E. and Hyman, S.L. (2005) Novel treatments for autistic spectrum disorders. Mental Retardation and Developmental Disabilities Research Reviews, 11, 131-142. doi:10.1002/mrdd.20062

[18] Wan, C.Y., Demaine, K., Zipse, L., Norton, A. and Schlaug, G. (2010) From music making to speaking: Engaging the mirror neuron system in autism. Brain Research Bulletin, 82, 161-168. doi:10.1016/j.brainresbull.2010.04.010

[19] Fong, C.E. and Mohd Jelas, Z. (2010) Music education for children with autism in Malaysia. Procedia Social and Behavioral Sciences, 9, 70-75.

[20] Holck, U. (2011) Music therapy research-children with an autism spectrum disorder. Tidsskrift for Dansk Musikterapi, 8, 27-35.

[21] Wigram, T. and Gold, C. (2006) Music therapy in the assessment and treatment of autistic spectrum disorder:
Clinical application and research evidence. Child: Care, Health and Development, 32, 535-542. doi:10.1111/j.1365-2214.2006.00615.x

[22] Trevarthen, C. (2001) Autism, sympathy of motives and music therapy. Enfance, 1, 86-99.

[23] Kim, J., Wigram, T. and Gold, C. (2009) Emotional, motivational and interpersonal responsiveness of children with autism in improvisational music therapy. Autism, 13, 389-409. doi:10.1177/1362361309105660

[24] Loukas, M., Saad, Y., Tubbs, R.S. and Shoja, M.M. (2010) The heart and cardiovascular system in the Qur'an and Hadeeth. International Journal of Cardiology, 140, 1923. doi:10.1016/j.ijcard.2009.05.011

[25] Green, M.H. (2004) Religion and medicine in the middle ages. Bulletin of the History of Medicine, 78, 709-710. doi:10.1353/bhm.2004.0118

[26] Yearl, M.K.K. (2003) Religion and medicine in the middle ages. Journal of the History of Medicine and Allied Sciences, 58, 90-92. doi:10.1093/jhmas/58.1.90

[27] Kahl, O. (2008) Medieval Islamic medicine. Bulletin of the History of Medicine, 82, 706-707. doi:10.1353/bhm.0.0091

[28] Azadboni, R.M. and Rabinataj, S.A. (2011) Faith, health and psychology. Procedia-Social and Behavioral Sciences, 30, 1530-1533. doi:10.1016/j.sbspro.2011.10.296

[29] Yousofi, H. (2011) Human health and religious practices in Quraan. Procedia-Social and Behavioral Sciences, 30, 2487-2490. doi:10.1016/j.sbspro.2011.10.485

[30] Levin, J. (2009) How faith heals: A theoretical model. Explore, 5, 77-96. doi:10.1016/j.explore.2008.12.003

[31] MacPhee, M. (2003) Medicine for the heart: The embodiment of faith in Morocco. Medical Anthropology, 22, 53-83. doi:10.1080/01459740306766

[32] Kirmayer, L.J. (2004) The cultural diversity of healing: Meaning, metaphor and mechanism. British Medical Bulletin, 69, 33-48. doi:10.1093/bmb/ldh006

[33] BaHammam, A.S. and Gozal, D. (2012) Quranic insights into sleep. Nature and Science of Sleep, 4, 81-87.

[34] Bahammam, A.S. (2011) Sleep from an Islamic perspective. Annals of Thoracic Medicine, 6, 187-192. doi:10.4103/1817-1737.84771

[35] Tumiran, M.A., Mohd. Saat, R., Abdul Rahman, N.N. and Hasan Adli, D.S. (2010) Sleep from neuroscience and Islamic perspectives: Comprehension and practices of Muslims with science background in Malaysian education system. Procedia Social and Behavioral Sciences, 9, 560564. doi:10.1016/j.sbspro.2010.12.197

[36] Kandel, E.R., Schwartz, J.H., Jessell, T.M., Siegelbaum, S.A. and Hudspeth, A.J. (2013) Principles of neural science. 5th Edition, McGraw Hill Professional, New York.

[37] Hardeland, R. (2012) Melatonin in aging and diseasemultiple consequences of reduced secretion, options and limits of treatment. Aging and Disease, 3, 194-225.

[38] Kotronoulas, G., Wengstrom, Y. and Kearney, N. (2012) A critical review of women's sleep-wake patterns in the context of neo-/adjuvant chemotherapy for early-stage breast cancer. Breast, 21, 128-141. 
doi:10.1016/j.breast.2011.12.004

[39] Magee, C.A., Kritharides, L., Attia, J., McElduff, P. and Banks, E. (2012) Short and long sleep duration are associated with prevalent cardiovascular disease in Australian adults. Journal of Sleep Research, 21, 441-447. doi:10.1111/j.1365-2869.2011.00993.x

[40] Richdale, A.L. (1999) Sleep problems in autism: Prevalence, cause, and intervention. Developmental Medicine \& Child Neurology, 41, 60-66. doi:10.1017/S0012162299000122

[41] Goodlin-Jones, B.L., Tang, K., Liu, J. and Anders, T.F. (2008) Sleep patterns in preschool-age children with autism, developmental delay, and typical development. Journal of the American Academy of Child and Adolescent Psychiatry, 47, 930-938.

[42] Turek, F.W. and Gillette, M.U. (2004) Melatonin, sleep, and circadian rhythms: Rationale for development of specific melatonin agonists. Sleep Medicine, 5, 523-532. doi:10.1016/j.sleep.2004.07.009

[43] Durmer, J.S. and Dinges, D.F. (2005) Neurocognitive consequences of sleep deprivation. Seminars in Neurology, 25, 117-129. doi:10.1055/s-2005-867080

[44] Van Der Heijden, K.B., Smits, M.G., Van Someren, E.J.W., Ridderinkhof, K.R. and Gunning, W.B. (2007) Effect of melatonin on sleep, behavior, and cognition in ADHD and chronic sleep-onset insomnia. Journal of American Academy of Child and Adolescent Psychiatry, 46, 233-241. doi:10.1097/01.chi.0000246055.76167.0d

[45] Blask, D.E. (2009) Melatonin, sleep disturbance and cancer risk. Sleep Medicine Reviews, 13, 257-264. doi:10.1016/j.smrv.2008.07.007

[46] Orzeł-Gryglewska, J. (2010) Consequences of sleep deprivation. International Journal of Occupational Medicine and Environmental Health, 23, 95-114. doi:10.2478/v10001-010-0004-9

[47] Øyane, N.M.F. and Bjorvatn, B. (2005) Sleep disturbances in adolescents and young adults with autism and Asperger syndrome. Autism, 9, 83-94. doi:10.1177/1362361305049031

[48] Buckley, A.W., Jennison, K., Buckley, J., Thurm, A., Sato, S. and Swedo, S. (2010) REM sleep percentage in children with autism compared to children with developmental delay and typical development. Archives of Pediatrics and Adolescent Medicine, 164, 1032-1037. doi:10.1001/archpediatrics.2010.202

[49] Durand, V.M. (2002) Treating sleep terrors in children with autism. Journal of Positive Behavior Interventions, 4, 66-72. doi:10.1177/109830070200400201

[50] Malow, B.A., Marzec, M.L., McGrew, S.G., Wang, L., Henderson, L.M. and Stone, W.L. (2006) Characterizing sleep in children with autism spectrum disorders: A multidimensional approach. SLEEP, 29, 1563-1571.

[51] Vriend, J.L., Corkum, P.V., Moon, E.C. and Smith, I.M. (2011) Behavioral interventions for sleep problems in children with autism spectrum disorders: Current findings and future directions. Journal of Pediatric Psychology, 36, 1017-1029. doi:10.1093/jpepsy/jsr044

[52] Chez, M.G., Buchanan, T., Aimonovitch, M., Mrazek, S.,
Krasne, V., Langburt, W., et al. (2004) Frequency of EEG abnormalities in age-matched siblings of autistic children with abnormal sleep EEG patterns. Epilepsy \& Behavior, 5, 159-162. doi:10.1016/i.yebeh.2003.11.019

[53] Hoffman, C.D., Sweeney, D.P., Gilliam, J.E. and LopezWagner, M.C. (2006) Sleep problems in children with autism and in typically developing children. Autism and Other Developmental Disabilities, 21, 146-152. doi:10.1177/10883576060210030301

[54] Hoffman, C.D., Sweeney, D.P., Gilliam, J.E., Apodaca, D.D., Lopez-Wagner, M.C. and Castillo, M.M. (2005) Sleep problems and symptomology in children with autism. Focus on Autism and Other Developmental Disabilities, 20, 194-200. doi:10.1177/10883576050200040101

[55] Hodge, D., Parnell, A.M.N., Hoffman, C.D. and Sweeney, D.P. (2012) Methods for assessing sleep in children with autism spectrum disorders: A review. Research in Autism Spectrum Disorders, 6, 1337-1344. doi:10.1016/j.rasd.2012.05.009

[56] Werner, H., Molinari, L., Guyer, C. and Jenni, O.G. (2008) Agreement rates between actigraphy, diary, and questionnaire for children's sleep patterns. Archives of Pediatrics \& Adolescent Medicine, 162, 350-358. doi:10.1001/archpedi.162.4.350

[57] Goldman, S.E., McGrew, S., Johnson, K.P., Richdale, A.L., Clemons, T. and Malow, B.A. (2011) Sleep is associated with problem behaviors in children and adolescents with autism spectrum disorders. Research in Autism Spectrum Disorders, 5, 1223-1229. doi:10.1016/j.rasd.2011.01.010

[58] Cotton, S.M. and Richdale, A.L. (2010) Sleep patterns and behaviour in typically developing children and children with autism, down syndrome, prader-willi syndrome and intellectual disability. Research in Autism Spectrum Disorders, 4, 490-500. doi:10.1016/j.rasd.2009.11.006

[59] Schreck, K.A., Mulick, J.A. and Smith, A.F. (2004) Sleep problems as possible predictors of intensified symptoms of autism. Research in Developmental Disabilities, 25, 57-66. doi:10.1016/j.ridd.2003.04.007

[60] Wiggs, L. and Stores, G. (2004) Sleep patterns and sleep disorders in children with autistic spectrum disorders: Insights using parent report and actigraphy. Developmental Medicine \& Child Neurology, 46, 372-380. doi:10.1017/S0012162204000611

[61] Wiggs, L., Montgomery, P. and Stores, G. (2005) Actigraphic and parent reports of sleep patterns and sleep disorders in children with subtypes of attention-deficit hyperactivity disorder. SLEEP, 28, 1437-1445.

[62] Corkum, P., Tannock, R., Moldofsky, H., Hogg-Johnson, S. and Humphries, T. (2001) Actigraphy and parental ratings of sleep in children with attention-deficit/hyperactivity disorder (ADHD). SLEEP, 24, 303-312.

[63] Lam, J.C., Mahone, E.M., Mason, T.B.A. and Scharf, S.M. (2011) Defining the roles of actigraphy and parent logs for assessing sleep variables in preschool children. Behavioral Sleep Medicine, 9, 184-193. doi:10.1080/15402002.2011.583906

[64] Sitnick, S.L., Goodlin-Jones, B.L. and Anders, T.F. (2008) 
The use of actigraphy to study sleep disorders in preschoolers: Some concerns about detection of nighttime awakenings. SLEEP, 31, 395-401.

[65] Hyde, M., O’Driscoll, D.M., Binette, S., Galang, C., Tan, S.K., Verginis, N., Davey, M.J. and Horne, R.S.C. (2007) Validation of actigraphy for determining sleep and wake in children with sleep disordered breathing. Journal of Sleep Research, 16, 213-216. doi:10.1111/j.1365-2869.2007.00588.x

[66] Allik, H., Larsson, J.-O. and Smedje, H. (2006) Insomnia in school-age children with asperger syndrome or highfunctioning autism. BMC Psychiatry, 6, 18-29. doi:10.1186/1471-244X-6-18

[67] Taylor, M.A., Schreck, K.A. and Mulick, J.A. (2012) Sleep disruption as a correlate to cognitive and adaptive behavior problems in autism spectrum disorders. Research in Developmental Disabilities, 33, 1408-1417. doi:10.1016/j.ridd.2012.03.013

[68] Park, S., Cho, S.-C., Cho, I.H., Kim, B.-N., Kim, J.-W., Shin, M.-S. et al. (2012) Sleep problems and their correlates and comorbid psychopathology of children with autism spectrum disorders. Research in Autism Spectrum Disorders, 6, 1068-1072. doi:10.1016/j.rasd.2012.02.004

[69] Tsai, F.-J., Chiang, H.-L., Lee, C.M., Gau, S. S.-F., Lee, W.-T., Fan, P.-C., et al. (2012). Sleep problems in children with autism, attention-deficit hyperactivity disorder, and epilepsy. Research in Autism Spectrum Disorders, 6, 413- 421. doi:10.1016/j.rasd.2011.07.002

[70] Lippi, D., Di Sarsina, P.R. and D’Elios, J.P. (2010) Music and medicine. Journal of Multidisciplinary Healthcare, $\mathbf{3}$, 137-141. doi:10.2147/JMDH.S11378

[71] Erkkila, J., Punkanen, M., Fachner, J., Ala-Ruona, E., Pontio, I., Tervaniemi, M., Vanhala, M. and Gold C. (2011) Individual music therapy for depression: Randomised controlled trial. The British Journal of Psychiatry, 199, 132-139. doi:10.1192/bjp.bp.110.085431

[72] Boyd-Brewer, C. and McCaffrey, R. (2004) Vibroacoustic sound therapy improves pain management and more. Holistic Nursing Practice, 18, 111-118.

[73] Thaut, M.H., Gardiner, J.C., Holmberg, D., Horwitz, J., Kent, L., Andrews, G., Donelan B. and Mclntosh, G.R. (2009) Neurologic music therapy improves executive function and emotional adjustment in traumatic brain injury rehabilitation. Annals of the New York Academy of Sciences, 1169, 406-416.

doi:10.1111/j.1749-6632.2009.04585.x

[74] Knight, A.J. and Wiese, N. (2011) Therapeutic music and nursing in poststroke rehabilitation. Rehabilitation Nursing, 36, 204-215. doi:10.1002/j.2048-7940.2011.tb00196.x

[75] Brotons, M. and Koger, S. M. (2000) The impact of music therapy on language functioning in dementia. Journal of Music Therapy, 37, 183-195.
[76] Kisilevsky, B.S., Hains, S.M.J., Jacquet, A.-Y., GranierDeferre, C. and Lecanuet, J.P. (2004) Maturation of fetal responses to music. Developmental Science, 7, 550-559. doi:10.1111/j.1467-7687.2004.00379.x

[77] Rabah, S. (2004) The Arabs contribution to music of the western world. FSTC Limited, Oxford.

[78] Elkadi, A. (1985) Health and healing in the Quran. American Journal of Islamic Social Sciences, 2, 291-296.

[79] Redha, M. (1999) AI-farouk omar ibn ai-khattab: The second caliph. Dar Al-Kotob Al-Ilmiyah, Beirut.

[80] Taslaman, C. (2006) The Quran: Unchallengeable miracle. Nettleberry/Çitlembik Publications, South Dakota.

[81] Yohan, K. dan H. (2012) Al'Quran therapy for increasing awareness to drowsy driver. 3rd Exposition on Islamic Innovation 2012 (I-Inova2012), Universiti Sains Islam Malaysia, Nilai.

[82] Khan, N., Ahmad, N, Beg, A.H., Fakheraldin, M.A.I., Abd Alla, A.N. and Nubli, M. (2010) Mental and spiritual relaxation by recitation of the holy Quran. 2nd International Conference on Computer Research and Development, Kuala Lumpur, 7-10 May 2010, 863-867.

[83] Abdullah, A.A. and Omar, Z. (2011) The effect of temporal EEG signals while listening to Quran recitation. International Journal on Advanced Science, Engineering and Information Technology, 1, 372-375.

[84] Zulkurnaini, N.A., Kadir, R.S.S.A., Murat, Z.H. and Isa, R.M. (2012) The comparison between listening to alQuran and listening to classical music on the brainwave signal for the alpha band. 3rd International Conference on Intelligent Systems Modelling and Simulation, Sabah, 8-10 February 2012, 181-186. doi:10.1109/ISMS.2012.60

[85] Aftanas, L.I. and Golocheikine, S.A. (2001) Human anterior and frontal midline theta and lower alpha reflect emotionally positive state and internalized attention: Highresolution EEG investigation of meditation. Neuroscience Letters, 310, 57-60. doi:10.1016/S0304-3940(01)02094-8

[86] Müller, R.A., Behen, M.E., Rothermel, R.D., Chugani, D.C., Muzik, O., Mangner, T.J., et al. (1999) Brain mapping of language and auditory perception in high-functioning autistic adults: A PET study. Journal of Autism and Developmental Disorders, 29, 19-31. doi:10.1023/A:1025914515203

[87] Gathercole, S.E. (1995) Is nonword repetition a test of phonological memory or long-term knowledge? It all depends on the nonwords. Memory \& Cognition, 23, 83-94. doi:10.3758/BF03210559

[88] Adam, S. (2010) Can't learn a foreign language? Not true, say scientist.

http://www.telegraph.co.uk/science/science-news/820095 6/Cant-learn-a-foreign-language-Not-true-say-scientists.h $\underline{\mathrm{tml}}$ 